\title{
Justification as a Social Activity
}

\author{
William Riordan $0^{\prime}$ Connor \\ Fordham University
}

We have no absolutely conclusive evidence that there is a pliysical world and we have no absolutely conclusive evidence either that we exist. But we have good inductive evidence for both assumptions.'

I once received a letter from an eminent logician, Mrs. Christina Ladd Eranklin, saying that she was a solipsist and was surprised there were no others. ${ }^{2}$

This paper will examine the problem of why it is that philosophers tend to say such strange things. Philosophy is perhaps most closely associated in the minds of those who have had a passing acquaintance with the subject with the problems of the existence of the external world and of other minds. It is not terribly surprising, then, that philosophers have had a reputation for becoming involved in trivial and inconsequential issues. Philosophers, of course, remain convinced of the seriousness of their work and appear to be quite willing to endure a lack of understanding on the part of the general public, perhaps believing the contempt of the mob to be the price of genius. And yet, we sometimes find philosophers saying things tluat are so extremely odd, if not downright silly, that we might feel that perhaps there is something to the suspicions of the public.

Since the time of Descartes, who can truly be said to be the father of a good many epistemological problems that are still with us, there has been a tendency for philosophers to view justification primarily as a private activity and only secondarily as a public or social activity. This is a fundamental erior that gives rise to such traditional staples of epistemology as the problem of the existence of the external world. the problem of other minds, and to such positions as those expressed in the above guotations.

In what follows it will be attempted (1) to illustrate how the belief that justification is primarily a private activity arises, (2) to show how this belief 
can generate the above-mentioned problems and positions, and (3) to show how this belief, and the problems engendered by $1 t$, can be avoided by paying careful attention to how our ability to justify beliefs originates.

An examination of justification should be careful to sort out three separate although interrelated issues: What is justification? How is it used? What is its origin? This paper will concentrate upon the last question in the belief that learning about the origin of justification will serve to shed light on what it is.

\section{I}

The first task, to illustrate how the belief that justification is primarily a private activity arises, can be approached by taking a closer look at the three elements in the traditional analysis. of knowledge as justified true belief."

The first element, belief, is subjective. By this it is not meant that belief is purely subjective in the sense that it is somehow totaliy independent of external reality. Obviously, a belief is a belief about something and in this sense at the very least it is related to something external somewhere along the line, if not immediately. Rather, what is meant is that belief is a condition, a state, of a knower. It is an attribute of a person, a subject.

The second element, truth, is objective. By this we mean simply that whatever it is that makes a statement true is somehow independent of the consciousness of the individual knower." Most philosophers would agree that truth, considered abstractly and absolutely, is conceived of as something the would-be knower strives after and does not create by himself. It is in this rather simple sense that we call truth 'objective' and this should not be a controversial point."

The third element in knowledge is justification. A general formula for justification is that $S$ is completely justified in believing that $p$ if he has evidence $e$ which entail $p$. But it is rather difficult to point out the exact character of justification all at once. For justification seems to have both public and private aspects. The public aspects of justification are obvious enough. We make a knowledge claim to another person or to a group of persons and if it is challenged we attempt to justify our knowledge claim. This happens frequently enough so that the public aspect of justification should be obvious to all.

But what of the private aspect of justification? clearly we have occasion to justify our knowledge claims to other people. It is just as clear that we do not ordinarily make knowledge claims to ourselves and then demand justifications. Indeed, we do not make 
knowledge claims to ourselves at all, we simply know things.

But do we ever justify anything to ourselves? Certainly we do. While we do not make or justify knowledge claims to ourselves, we do justify to ourselves propositions which are candidates for belief. There are numerous examples of this, such as the hunter by himself in the woods trying to determine if the tracks he sees are those of the animal he is hunting. Whenever a person is alone and checks, without consulting others, to see if he has reached the true solution to a particular problem or when a scientist goes over the results of an experiment by himself to see if he really has made a discovery, we have an instance of private justification. The subjective and private aspect of justification, then, is no less real than the social and public aspect.

But, granted that justification has both public and private aspects, we are faced with the problem of determining which aspect is prior. The problem comes down to this: Is justification primarily a private, subjective activity and only secondarily a public, social one, or vice versa? Does justification originate in individuals or does it originate only in a social context?

Now in the introduction it was stated that many of the traditional problems of epistemology can arise from viewing justification primarily as a private activity and only secondarily as a public activity. The activity of private justification is viewed as being somehow prior to the public justification of a knowledge claim. In this section we wish to illustrate, through an examination of the elements of the traditional analysis of knowledge, how this belief can arise. So let us now proceed to attempt to reconstruct the general lines of reasoning that can lead philosophers to this conclusion. Keith Lehrer, one of the foremost proponents of the sceptical position in contemporary epistemology, provides us with a number of statements with which we can construct arguments for the fundamentally private nature of justification.

It seems to be the case that justification must be primarily a private activity, for at least two reasons. The first is that justification depends upon evidence and the apprehension of evidence looks to be a private matter. lt is simply true as a matter of fact that some people notice things and others do not. Thus, even where the access to evidence is public, its acquisition--noticing it--is basically a private activity. Now since justification depends upon evidence, and since noticing evidence would seem to be a private activity, justification itself would also be a private activity. Lehrer has emphasized the central role of evidence in justification and explicitly points out the variation in the apprehension of evidence: 
When we say that $s$ is completely justified, we shall mean that if his belief is based upon evidence, then he is completely justified by the evidence he has in believing that $p$. Thus, that I am completely justified in believing that $p$ by the evidence that I have does not by itself warrant my saying that another is completely justified in his belief that $p$. He too must have evidence which completely justifies his belief before he is, in the reguired sense, completely justified in believing that p."

The second reason why justification would seem to be primarily a private activity is that justification deals exclusively with beliefs. For something to be taken as evidence we must give assent to it, i.e.. we must believe it. What we do in justification, then, is to relate propositions to our other beliefs. This holds true for both of the theories of justification that Lehrer discusses in his book. Knowledge:

The first (theory) assumes, with the correspondence theory (of truth), that there are certain basic facts, and that all beliefs that are justi$f i e d$ are so by their relation to those facts. Beliefs concerning basic facts are basic beliefs. All other beliefs are justified in terms of basic beliefs.. . . The second kind (of theory)... posits that the justification of beliefs depends only upon relations between beliefs in some system of beliefs none of which is basic.'

In both therories, then, justification is a matter of relations among beliefs. Lehrer later goes on to assert that in all cases, including social situations, a person can justify his beliefs only by appealing to other beliefs:

In whatever way a man might attempt to justify his beliefs, whether by himself or to another, he must always appeal to some belief. There is nothing other than one's belief to which one can appeal in the justification of belief."

Now since in all cases justification deals with beliefs and since belief, as we have see:!, is a subjective element in knowledge, justificatic $n$ will appear to be primarily a private activity.

We have now seen how the belief $t$ : at justification is primarily a private activity ari:es. The basic paradigm is the following: a perso: forms a belief, justifies it to himself in some way, publicly makes a knowledge claim, and, if his claim is challenged or if circumstances otherwise require it, he reproduces his private justification for others. It cannot be denied 
that this is very often the case. In fact, part of the plausibility of the position that justification is primarily a private activity stems from the fact that this paradigm does indeed represent the usual way in which knowledge is advanced. The real danger lies in taking this to be the universal paradigm for knowing. This will be discussed in the fourth section of this paper. Now we must take a look at how this paradigm generates the traditional problems of epistemology.

\section{I I}

We have taken an analysis of knowledge as justified true belief as a starting point and have, for the sake of argument, adopted the position that justification is primarily a private, subjective activity. Taking this as a universal paradigm for knowledge, a person must now justify to himself and 'on his own' all his beliefs before he can legitimately make any knowledge claims regarding them. It is quite easy to see how the traditional problems of epistemology arise in the context of such a project. For one thing, the would-be knower is working with beliefs and justification. Since in the analysis of knowledge we are considering these are subjective elements, the person is trapped in a 'circle of subjectivity' with no clear way out. He is always of necessity dealing with private 'material'. Lehrer explicitly embraces this view:

There is no exit from the circle of one's beliefs. This might not seem obvious. It might, for instance, seem that one can appeal directly to experience, or the testimony of others, to justify one's beliefs. But this is illusory. Sense experience, whether commonly casual or carefully controlled, always leaves open the question of what we are to believe. The prick of sense often elicits ready consent, but what we believe in the face of sensory stimulation depends on our antecedent convictions.'

Since the communication of information is such an important part of human experience, this private justification of all our knowledge claims is of the utmost importance to philosophy. We are thus placed in a situation not too dissimilar to that of Descartes at the beginning of the Meditations.

In fairness to Descartes, it should be said that given the presuppositions of his rationalism, his program makes perfectly good sense. For if the world is a system of necessarily related events, then simply by knowing one event--the cogito--one can in theory. by just tracing its relations to other events, finally come to a knowledge of the entire system of events. What is amazing is that long after the presuppositions 
of rationalism have been abandoned philosophers are still following in the footsteps of Descartes and encountering the same problems, the existence of the self, of the external world, and of other minds, that he encountered. This is an indication not so much of the enduring influence of Descartes, although that should not be underestimated, as it is of the continuing appeal of the conception of science as a system of interrelated truths founded upon a basic truth.

But once we have to justify all our knowledge claims, we will learn by experience to make very few. Consider, for example, A. J. Ayer's well-known comments on the Cartesian cogito:

But even if it were true that such a proposition as 'there is a thought nc.w' was logically certain, it still would not serve Descartes' purpose. For if 'cogito' is taken in this sense, his initial principle, 'cogito ergo sum.' is false. 'I exist' does not follow from 'there is a thought now'. The fact that a thought occurs at any given moment does not cntail that any other thought has occurred at : iy other moment. still less that there has occurl:d a series of thought sufficient to constitute a single self.'0

The validity of the deductions that Descartes makes from the cogito have rightly been subject to attack. But some philosophers have gone on to maintain that we cannot know that we exist. Hans Reichenbach, for example, concluded that the existence of the self is what he terms a 'posit', an assumption that we make on the basis of good inductive evidence that is not absolutely comclusive.12 of course, if there are problems with the existence of the self (apart from the very real problem of the nature of the self) then there must also be problems with the existence of the external world and the existence of other minds for the would-be knower. We can now see that when one views justification as primarily a private activity the traditional problems of epistemology arise. Now we must see if there is any way in which they can be avoided.

The belief that justification is primarily private and the problems this belief generates can be avoided if we pay close attention to the activity we call justifying. In his review of Lehrer's Knowledge, Alan White points out an important distinction. Here White claims that Lehrer

. . slides--at first implicitly.. and then explicitly. . .-from an examination of the conditions for someone's having knowledge to an ex- 
amination of the condition for someone's claim to have knowledge to be justified. ${ }^{12}$

This distinction between knowing and claining to know is very important for the matter we are considering. Eor there are situations in which we would say that a person knows something and yet is unable to justify a claim to know. An obvious example would be an infant knowing her mother. This distinction would seem to suggest that justification is more pertinent to claiming to know than to knowing proper. This is important because claiming to know is something that always occurs in a social context. Once again, we do not make knowledge claims to ourselves, we simply know things. We will return to this point iater.

In trying to discover exactly what justification is, we can use Gilbert Ryle's distinction between knowing that and knowing how." It may be objected that even granted that justification presupposes a knowing how, it is something we somelow 'intuit' how to do or that it is a natural human ability like breathing or walking and that everyone who has the ability does it with pretty much the same degree of competence. But this is obviously not the case. Some people have difficulty articulating their beliefs, let alone organizing and relating them in complex patterns or supporting them with relevant evidence.. Being able to justify. then, is clearly a skill.

The question which must now be asked is, 'What is the origin of this skill? How do we develop it?' A clue comes from Wilfrid Sellars. Discussing the origin of concepts referring to inner episodes, he states that they are intersubjective, in other words, that we get them from other people in a social situation." Now if the very activity that we call justifying is intersubjective in its origin, then it follows that the $\in x-$ istence of this activity presupposes the existence at some time of a community whose members make knowledge claims. The existence of such a community of people is a necessary condition for the existence of the activity of justifying. A theory of justification, then, may correctly begin by recognizing the existence of such a comunity as an eminentiy reasonable presupposition. ${ }^{\text {is }}$ a

We are now in a position to indicate what justification is. Justification has public and private aspects but its origin is intersubjective. As such, it is primarily a social activity. Before we can know bout justifying it and knowing how to justify something. i.e. how to relate a belief to other beliefs by articulating them and arranging them or how to support a belief by appeal to relevant evidence, is a skill, something we learn how to do, something we acquire as members of an epistemic community. Once we learn how to justify our beliefs through obseiving other people 
performing justifications, we internalize the process and perform private justifications either in anticipation of a public demand for them or for our own satisfaction. 16

The two arguments given for the fundamentally private nature of justification can be dismissed. With regard to the first, it is quite true that noticing evidence is something that is private, but we learn how to notice things--how to be observant, how to focus our attention--from other people who point things out to us, show us what to look for. The second argument states that justification deals exclusively with beliefs. But how to organize and support beliefs by evidence is something that we clearly pick up in a socjal context. One must always be careful to distinguish between the way we justify and the way in which we learn to justify if the social nature of justification is to be made clear.

on the view that justification is primarily a social activity, it follows that the existence of justification presupposes a community of people who claim to know. The demand to justify the presuppositions of justification is clearly an unreasonable one. Thus, attempting to justify belief in the existence of the self, the external world, other minds, or an epistemic community is mistaken. These facts are known without need for justification. Problems and scepticism concerning these facts arise when philosophers ignore the practical limits of the concept of justification. They will disappear when philosophers recognize these limits and obey them."'

\section{NOTES}

'Hans Reichenbach, The Rise of Scientific
Philosophy, (Los Angeles: University of Caiffornia Press, 1059), p. 268.

${ }^{2}$ Bertrand Russe11, Human Knowledge: Its Scope and Limits. (New York: Simon and Schuster, 1948), p. 180 .

${ }^{3}$ This analysis of knowledge is sometimes traced back to the final definition of knowledge given in Plato's Theaetetus $(201 c-210 d)$. It should be pointed out that Plato rejects this definition precisely because of the difficulty involved in determining the meaning of 'logos'. In this paper we are adopting the traditional analysis of knowledge merely to illustrate how the belief that justification is p:imarily a private a:tivity can arise. This should not be construed as an endorsement of the traditional analysis. 
"The problem here, of course, is to give a characterization of truth that is broad enough to apply to all the various theories of truth. Even with this vague characterization of truth a problem crops up regarding statements describing the conscious state of the speaker, e.g.. 'I am thinking about going to Paris'. But in such cases the goal must be to give an accurate description of the conscious state if the statement is to be true. Thus, one can still maíntain that truth is an objective element in these cases as well in the sense that it is someting to strive for.

sAn interesting alternative to the traditional analysis of the relationship between knowledge and truth can be found in certain forms of Idealism. Here the notion that truth transcends knowledge is rejected.

But even in Idealism there remains a problem of objectivity. See Graham McFee, "How to be an Idealist," Idealistic studies, XI, 3 (September 1981), pp. 280-284.

'Keith Lehrer, Knowledge, (Oxford: Oxford University Press, 1974), Pp. 13-14.

'Lehrer, p. 75 .

'Lehrer, pp. 187-188.

'Lehrer, p. 188.

$1 \%$. J. Ayer, Language, Truth, and Logic, (New York: Dover, 1952), P. 47.

${ }^{11}$ Reichenbach, p. 35 .

12 Alan White, "Review of Knowledge by Keith Lehrer," The Philosophical Quarterly, vol. 25, no. 100 (July 1975), pp. 284-285. Also, see Wilte's On Claiming to know" The Philosophical Review, vol. 66 (1957), pp. 180-192.

"Gilbert Ryle, "knowing How and knowing That," Proceedings of the Aristotelian Society. XLVI (194546), pp. $1-16$.

"Wilfrid Sellars, "Empiricism and the Philosophy of Mind," Minnesota studies in the Philosophy of Science, vol. I. $\mathrm{H}$. Feigl and $\bar{M}$. Scriven, eds., (Minneapolis, MN: University of Minnesota Press, 1956), pp. 253-329.

${ }^{15}$ Roderick M. Chisholm's procedure is entirely correct here: "We presuppose, first, that there is something that we know and we adopt the working hypothesis that what we know is pretty much that which, 
on reflection, we think we know. This may seem the wrong place to start. But where else could we start?" Theory of Knowledge, second edition, (Englewood Cliffs, New Jersey: Prentice-Hall, 1977), p. 16.

is It should be pointed out that that this position relates to certain beliefs about social organization and learning theory, which are the subject of empirical investigation.

17 An earlier version of the paper was read at the Metropolitan Regional Conference of the American Catholic Philosophical Association held at Fordham University on December 6,1980 . The author is grateful to the Rev. Vincent $M$. Cooke, S.J.. formerly of the Department of Philosophy, Fordham University, for reading the original version of this paper. 